\title{
0xidative stress parameters in patients with prostate cancer, benign prostatic hyperplasia and asymptomatic inflammatory prostatitis: A prospective controlled study
}

\author{
Engin Kaya ${ }^{1, A-F}$, Yasar Ozgok ${ }^{2, F}$, Murat Zor, ${ }^{3, D, E}$, Ayse Eken ${ }^{4, C}$, Selahattin Bedir ${ }^{2, E, F}$, Onur Erdem ${ }^{4, B, C}$, Turgay Ebiloglu ${ }^{5, B, C}$, Giray Ergin ${ }^{6, A, B}$ \\ ${ }^{1}$ Department of Urology, Gülhane Askeri Tip Akademisi (GATA), Ankara, Turkey \\ 2 Urology Department, Medical Faculty, Gülhane Military Medical Academy (GMMA), Ankara, Turkey \\ ${ }^{3}$ Department of Urology, Gülhane Askeri Tip Akademisi Haydarpasa Research Center, Istanbul, Turkey \\ ${ }^{4}$ Pharmacology Department, Medical Faculty, Gülhane Military Medical Academy (GMMA), Ankara, Turkey \\ ${ }^{5}$ Urology Department, Etimesgut Military Hospital, Turkey \\ ${ }^{6}$ Urology Department, Agrı Military Hospital, Turkey \\ A - research concept and design; $\mathrm{B}$ - collection and/or assembly of data; $\mathrm{C}$ - data analysis and interpretation; \\ $D$ - writing the article; $E$ - critical revision of the article; $F$ - final approval of article
}

Address for correspondence

Murat Zor

E-mail:murat804@yahoo.com

Funding sources

None declared

Conflict of interest

None declared

Received on July 4, 2015

Revised on November 22, 2015

Accepted on November 8, 2016

DOI

$10.17219 /$ acem $/ 66837$

Copyright

Copyright by Author(s)

This is an article distributed under the terms of the

Creative Commons Attribution Non-Commercial License

(http://creativecommons.org/licenses/by-nc-nd/4.0/)

\begin{abstract}
Background. The imbalance between oxidant and reductant mechanisms creates a nidus for the etiopathogenesis of several diseases. In this study, we aimed to compare the oxidative stress (OS) parameters in patients who were diagnosed with prostate cancer $(\mathrm{p}(\mathrm{a})$, benign prostatic hyperplasia (BPH) or asymptomatic inflammatory prostatitis (AIP), according to the histopathologic examination of transrectal ultrasonographic prostate biopsy and transurethral prostate resection specimens.
\end{abstract}

Objectives. In this study, we aimed to compare oxidative stress between histologically proven prostate cancer, hyperplasia and prostatitis.

Material and methods. According to histopathologic examinations, 97 patients were divided into 3 study groups: group 1: $p C a(n=30)$, group 2: BPH $(n=41)$, and group 3: AIP $(n=26)$. Finally, 30 patients were enrolled in a control group. MDA levels, CuZn-SOD, Se-GPx, CAT activities, and trace element levels were evaluated.

Results. A statistically significant difference between prostate cancer and other groups were documented in terms of MDA activity. Contrary to AIP, a statistically significant difference has also been encountered between BPH and the control group. Decreased CuZn-SOD enzyme levels were found in PCa and BPH patients without statistical significance. Increased CAT activity was also documented in PCa, BPH and AIP patients. No significant difference in GPX activity was documented between the groups, except BPH and control group. Trace element levels were low in the patients with prostate cancer and BPH when compared with the control group

Conclusions. Despite the data regarding OS in PCa patients, there is a paucity of data regarding BPH and especially AIP patients. Our study revealed obvious oxidative stress in BPH and PCa patients as opposed to AIP. Assessing the oxidative stress in these patients may assist in the future prevention, diagnosis and also treatment. However, the question whether the presence of OS-related parameters and drugs could be used for the diagnosis or management of prostatic diseases, needs to be addressed in future larger and better studies with a more rational basis.

Key words: prostate cancer, oxidative stress, chronic prostatitis, benign prostatic hyperplasia, prostate biopsy 
Oxidative stress (OS) is defined as the interruption of the balance between oxidant and reductant molecules due to the excessive production of reactive oxygen species (ROS). This imbalance leads to oxidative DNA damage and performs a nidus for the etiopathogenesis of several diseases. There is plenty of data regarding the relationship between ROS and age-related pathologies such as cancer, diabetes or several degenerative disorders. ${ }^{1}$ In regard to the prostate, the studies conducted in the last decade have demonstrated that OS is associated with prostate cancer $(\mathrm{PCa})$ development, progression and response to therapy. ${ }^{1,2}$ In the last years, a relationship between prostatic inflammation and benign prostatic hyperplasia (BPH) has also been suggested. ${ }^{3}$ Conversely, there is a paucity of data regarding the OS parameters in the asymptomatic inflammatory prostatitis (AIP) patients.

In this prospective controlled study, we aimed to compare the OS parameters in patients who were diagnosed with prostate cancer, $\mathrm{BPH}$ or AIP according to the histopathologic examination of transrectal ultrasonographic prostate biopsy (TRUS-Bx) and transurethral prostate resection (TURP) specimens.

\section{Material and methods}

\section{Subjects and study design}

This prospective controlled study was approved by the Ethical Committee of Gülhane Military Medical Academy, protocol number 1491-1175-10/1539, and conducted in accordance with the Declaration of Helsinki. Written informed consent was obtained from all the participants in the study group and before the collection of blood specimens. A total of 127 patients were enrolled to the study to form 3 study groups and a control group. According to the histopathologic examination of TRUS-Bx and TURP specimens, 97 patients were divided into 3 study groups: group 1 : prostate cancer $(n=30)$, group 2 : benign prostatic hyperplasia $(n=41)$, and group 3: asymptomatic inflammatory prostatitis $(\mathrm{n}=26)$. A final group of 30 patients with no lower urinary tract symptoms, normal PSA levels, normal digital rectal examination and no history of previous prostatitis treatment was enrolled as group 4 (control group).

\section{Inclusion and exclusion criteria}

Inclusion criteria: TRUS Bx performed on patients due to elevated serum PSA levels or abnormal digital rectal examination and TURP performed on patients due to lower urinary tract symptoms.

Exclusion criteria: Previous history of cancer treatment, presence of liver dysfunction, diabetes mellitus, heart failure or renal failure; smoking; chronic alcohol use, and oral antioxidant supplementation or any mineral supplementation at the moment of the enrollment.

\section{Sample collection and laboratory methods}

Blood samples were drawn from the antecubital vein following an overnight fast and distributed into evacuated tubes containing ethylendiaminetetraacetic acid (EDTA). All samples were centrifuged for $10 \mathrm{~min}$ at $4000 \mathrm{~g}$ and $4^{\circ} \mathrm{C}$. After the plasma was separated, the buffy coat was removed and the packed cells were washed 3 times with 2 volumes of isotonic saline. Then, a known volume of erythrocytes was lysed with cold distilled water (1:4), stored in a refrigerator at $4^{\circ} \mathrm{C}$ for $15 \mathrm{~min}$ and the cell debris was removed by centrifugation $\left(2000 \mathrm{~g}\right.$ at $4^{\circ} \mathrm{C}$ for $10 \mathrm{~min}$ ). Plasma samples and erythrocyte lysates were stored at $-70^{\circ} \mathrm{C}$ until assayed. Copper and zinc-containing superoxide dismutase enzyme (CuZn-SOD), selenium-dependent glutathione peroxidase (Se-GPx) and catalase (CAT) activities were measured in the erythrocyte lysates on a UV-VIS recording spectrophotometer (UV-2100S, Shimadzu Co., Kyoto, Japan). Erythrocyte CuZn-SOD activity was measured as previously described by Eken et al. ${ }^{4}$ The measurement of erythrocyte CuZn-SOD enzyme activity was based on the generation of superoxide radicals produced by xanthine and xanthine oxidase, which react with INT to form a red formazan dye. CuZn-SOD activity is expressed in U/g Hb. Erythrocyte Se-GPx activity was measured as previously described by Tüzün et al. and expressed in U/g Hb. ${ }^{5}$ Erythrocyte CAT activity was measured in hemolysates at $25^{\circ} \mathrm{C}$ by the method developed by Aebi. ${ }^{6}$ The activity is expressed as $\mathrm{KU} / \mathrm{g} \mathrm{Hb}$. Lipid peroxidation was estimated by measuring thiobarbituric acid reactive substances in erythrocyte lysates by the method previously described by Eken et al. ${ }^{4}$ After malondialdehyde (MDA) reacted with thiobarbituric acid, the reaction product was followed spectrophotometrically at $532 \mathrm{~nm}$, using tetrametoxypropane as a standard. The results are expressed as $\mathrm{nmol} / \mathrm{mL}$. An atomic absorption spectrometer with a Zeaman background correction (PerkinElmer Analyst 800, Shelton, CT 06484-4794 USA) was used to detect the trace element levels: zinc $(\mathrm{Zn})$, copper $(\mathrm{Cu})$, and selenium $(\mathrm{Se})$ in plasma and erythrocyte samples.

\section{Statistical analysis}

Statistical Package for Social Sciences (SPSS) v. 15.0 was used as a software package for statistical evaluations. All results were presented as mean \pm standard deviation (SD). Conformity to the normal distribution of variables was assessed by the Kolmogorov-Smirnov test. In order to compare the continuous variables among groups, the ANOVA test was used. Pearson's correlation analysis was used to evaluate the relationship between variables. Ageadjusted analysis of covariance was used for comparisons. The values were considered statistically significant, if the p-value was less than 0.05 . 
Table 1. MDA, antioxidant enzyme and trace element levels according to the groups

\begin{tabular}{|c|c|c|c|c|}
\hline & $\mathrm{PCa}(\mathrm{n}=30)$ & $\mathrm{BPH}(\mathrm{n}=41)$ & $\operatorname{AIP}(n=26)$ & Control $(n=30)$ \\
\hline MDA (nmol/mL) & $12.26 \pm 3.08$ & $7.69 \pm 2.41$ & $6.66 \pm 1.73$ & $5.95 \pm 1.11$ \\
\hline CuZn-SOD (U/g Hb) & $615.29 \pm 142.28$ & $575.99 \pm 110.31$ & $647.80 \pm 39.71$ & $686.57 \pm 95.61$ \\
\hline CAT (KU/g Hb) & $62.21 \pm 10.67$ & $53.31 \pm 9.67$ & $57.44 \pm 11.68$ & $50.41 \pm 9.17$ \\
\hline Se-GPx (U/g Hb) & $5.18 \pm 1.18$ & $4.87 \pm 0.91$ & $5.45 \pm 0.65$ & $5.83 \pm 1.17$ \\
\hline $\mathrm{Cu}(\mu \mathrm{g} / \mathrm{mL})$ & $0.56 \pm 0.11$ & $0.51 \pm 0.08$ & $0.58 \pm 0.04$ & $0.63 \pm 0.08$ \\
\hline $\mathrm{Zn}(\mu \mathrm{g} / \mathrm{mL})$ & $7.89 \pm 1.53$ & $7.22 \pm 1.15$ & $8.10 \pm 0.62$ & $8.68 \pm 1.11$ \\
\hline Se (ng/mL) & $98.96 \pm 19.21$ & $91.08 \pm 14.16$ & $101.60 \pm 5.11$ & $111.41 \pm 11.67$ \\
\hline
\end{tabular}

PCa - prostate cancer; BPH - benign prostatic hyperplasia; AIP - asymptomatic inflammatory prostatitis; MDA - malondialdehyde; CuZn-SOD - copper and zinc-containing superoxide dismutase enzyme; Se-GPx - selenium-dependent glutathione peroxidase; CAT - catalase; Cu - copper; Zn - zinc; Se - selenium.

\section{Results}

Thirty newly diagnosed men with prostate cancer, 41 men with benign prostatic hyperplasia, 26 men with asymptomatic inflammatory prostatitis, and 30 control subjects were enrolled in the study. Mean patient ages were $65.16 \pm 8.40,68.65 \pm 7.35,64.76 \pm 8.09$ and $53.93 \pm 5.41$ years in prostate cancer, benign prostatic hyperplasia, asymptomatic inflammatory prostatitis and control groups, respectively. Total serum PSA levels were significantly high in the prostate cancer group when compared to other groups $(\mathrm{p}<0.001)$. On the other hand, there was no statistical difference between the groups in terms of height, weight, body mass index and hemoglobin levels $(\mathrm{p}>0.05)$.

MDA, antioxidant enzyme and trace element levels according to the groups are summarized in Table 1 , and the comparison of the groups according to the OS parameters is shown in Table 2. A statistically significant difference between prostate cancer and other groups were docu- mented in terms of MDA and catalase activity ( $<<0.05)$. The only exception was between prostate cancer and AIP group catalase activity. Prostate cancer patients had lower CuZn-SOD levels than control group patients but the difference was not statistically significant ( $p \geq 0.05$ ). $\mathrm{BPH}$ group had a lower CuZn-SOD, Se-GPx activity and a higher MDA activity when compared with the control group and all differences were statistically significant, except MDA activity $(\mathrm{p}<0.05)$. CAT activity was the second parameter to be found as statistically insignificant. The AIP group had comparable results with those of the control group. CAT activity was found to be significantly high in the AIP group ( $\mathrm{p}<0.05)$.

Trace element levels were significantly low in patients with prostate cancer and $\mathrm{BPH}$ when compared with the control group, and the differences were statistically significant. The only exception was the $\mathrm{Zn}$ levels between the group with prostate cancer and the control group. Again, there was no statistical significance between the AIP group and the control group in terms of trace elements.

Table 2. The comparison of the groups according to OS parameters

\begin{tabular}{|l|c|c|c|c|c|c|}
\hline \multicolumn{1}{|c|}{ Parameters } & PCa \& BPH & PCa \& AIP & PCa \& control & BPH \& AIP & BPH \& control & AIP \& control \\
\hline MDA & $<0.001$ & $<0.001$ & $<0.001$ & 0.454 & 0.068 \\
\hline CuZn-SOD & 0.762 & 1 & 0.130 & 0.05 & 0.004 \\
\hline CAT & 0.003 & 0.503 & 0.001 & 0.692 & 1 \\
\hline Se-GPx & 1 & 1 & 0.184 & 0.169 & 0.012 \\
\hline Cu & 0.099 & 1 & 0.043 & 0.015 & 0.267 \\
\hline Zn & 0.119 & 1 & 0.135 & 0.022 & $<0.001$ \\
\hline Se & 0.128 & 1 & 0.016 & 0.021 & $<0.001$ \\
\hline
\end{tabular}

$\mathrm{PCa}$ - prostate cancer; BPH - benign prostatic hyperplasia; AIP - asymptomatic inflammatory prostatitis; MDA - malondialdehyde; CuZn-SOD - copper and zinc-containing superoxide dismutase enzyme; Se-GPx - selenium-dependent glutathione peroxidase; CAT - catalase; Cu - copper; Zn - zinc; Se - selenium; $p<0.05$ considered as statistical significance. 


\section{Discussion}

Oxidative stress is the interruption of the balance between oxidant and reductant mechanisms and the excessive production of ROS. This imbalance leads to oxidative DNA damage and creates a nidus for the etiopathogenesis of several diseases. ${ }^{1}$ In relation to the prostate, there is plenty of data regarding the relationship between ROS species, OS and age-related pathologies, such as PCa, $\mathrm{BPH}$ and AIP. ${ }^{1-3}$ In our prospective controlled study, we aimed to investigated the OS parameters in patients with $\mathrm{PCa}, \mathrm{BPH}$ and AIP, and compared the results with a control group. All the patients were diagnosed according to the histopathologic examination of transrectal ultrasonographic (TRUS) prostate biopsy (Bx) and transurethral prostate resection (TURP) specimens.

While MDA, hydrogen peroxide, superoxide radical or nitric oxide can be used to evaluate OS status, several endogenous antioxidant enzymes including SOD, GPx, CAT, some trace elements including $\mathrm{Cu}^{+2}, \mathrm{Zn}^{+2}, \mathrm{Se}^{+2}$, and some molecules like vitamin $\mathrm{E}$, vitamin $\mathrm{C}$, transferrin and ceruloplasmin can be used in order to evaluate antioxidant capacity. ${ }^{7-10}$ In our cohort, we analyzed MDA, SOD, GPx, CAT and $\mathrm{Cu}^{+2}, \mathrm{Zn}^{+2}, \mathrm{Se}^{+2}$ to evaluate the OS status.

MDA levels are considered to be a valuable parameter to evaluate lipid peroxidation and OS. MDA is a highly reactive aldehyde and has the potential for DNA damage, probably leading to mutagenic, genotoxic and cytotoxic effects. ${ }^{11}$ While Dogru-Abbasoglu et al. did not find a significant difference in MDA levels in comparison to $\mathrm{PCa}$ and $\mathrm{BPH}$ patients, some other investigators documented significantly increased MDA levels in PCa patients when compared with $\mathrm{BPH}$ and control. ${ }^{12-17}$ In our study, a statistically significant difference between patients with prostate cancer and other groups was documented in terms of MDA activity. On the contrary, no statistically significant difference was encountered between AIP/control and $\mathrm{BPH} /$ control groups.

In the literature in English, there are debatable results regarding antioxidant activity in $\mathrm{PCa}$ or $\mathrm{BPH}$ patients. While some authors documented decreased activity, others revealed no change. ${ }^{18-20}$ In their study, Doğru-Abbasoglu et al. compared PCA and BPH patients in terms of SOD, CAT and GPx activity and showed no significant difference. ${ }^{11}$ Aydin et al. conducted a controlled study to evaluate antioxidant activity in the patients with $\mathrm{PCa}$ and $\mathrm{BPH}$ and revealed that $\mathrm{PCa}$ patients had decreased CuZn-SOD enzyme levels when compared with $\mathrm{BPH}$ and control. ${ }^{21}$ Jun-Fu Zhou et al. also demonstrated significantly decreased CuZn-SOD levels in chronic bacterial prostatitis (category 3), but the literature data regarding AIP patients is lacking. ${ }^{22}$ In our study, decreased CuZn-SOD enzyme levels were found to be lower in $\mathrm{PCa}$ and $\mathrm{BPH}$ patients, but these differences were statistically significant only for $\mathrm{BPH}$ and control group patients.
There are also conflicting results regarding CAT and GPx activity in PCa or BPH patients. Some authors demonstrated decreased activity while others showed no difference or increased activity. ${ }^{21,23-25}$ In their study, Biri et al. reported increased CAT and GPx activity in PCa patients when compared with $\mathrm{BPH}$ and control. ${ }^{25}$ They concluded that this increase was due to a rebound effect to increased oxidative stress in order to neutralize it. Our results also revealed increased CAT activity in $\mathrm{PCa}, \mathrm{BPH}$ and AIP patients when compared with the control group. The difference was statistically significant in PCa patients when compared with $\mathrm{BPH}$ and control group patients. But no significant difference in GPx activity was documented between groups, except BPH and control group.

$\mathrm{Cu}^{+2}$ and $\mathrm{Zn}^{+2}$ catalyze SOD enzyme and their levels are consistent with SOD levels. On the other hand, $\mathrm{Zn}^{+2}$ has an additional contribution to hormonal function on prostatic tissue. ${ }^{26}$ Yan et al. hypothesized that decreased levels of $\mathrm{Zn}^{+2}$ are associated with increased DNA damage. ${ }^{27}$ Christudoss et al. and Gomez et al. have found that $\mathrm{Zn}^{+2}$ levels were decreased in $\mathrm{PCa}$ patients when compared with control. ${ }^{28,29}$ In our study, $\mathrm{Zn}^{+2}$ levels were decreased in PCa, BPH and AIP groups when compared with control, but a statistically significant difference was observed only between $\mathrm{BPH}$ and control groups. Similar results were documented also for $\mathrm{Cu}^{+2}$ levels but the statistical significance was seen in both $\mathrm{PCa} /$ control and $\mathrm{BPH} /$ control groups.

$\mathrm{Se}^{+2}$, a trace element, is found to be protective against several malignancies with respect to several animal and cell culture studies. ${ }^{30}$ This is considered to be due to the induction of apoptosis, which prevents cellular proliferation and has a key role for GPx enzyme activity. ${ }^{31-33}$ There are some studies showing decreased levels in $\mathrm{PCa}$ and $\mathrm{BPH}$ patients, in contrast to some showing no difference. ${ }^{34-37}$ Our results revealed statistically decreased $\mathrm{Se}^{+2}$ levels in $\mathrm{PCa}$ and $\mathrm{BPH}$ groups when compared with control group.

\section{Conclusions}

Oxidative stress, interruption of the balance between oxidant and reductant mechanisms, can lead to several prostatic diseases. Although there is plenty of data regarding OS in PCa patients, there is a lack of data regarding $\mathrm{BPH}$ and especially AIP patients. Our prospective controlled study has its unique advantage of evaluating several OS parameters in these patients and showed obvious oxidative stress in $\mathrm{BPH}$ and PCa patients as opposed to AIP. Assessing the oxidative stress in these patients may assist in the future prevention, diagnosis and also treatment. Despite our encouraging results, whether the presence of OS-related parameters and drugs could be used for the diagnosis or management of prostatic diseases is something that needs to be addressed in several future larger and better studies with a more rational basis. 


\section{References}

1. Paschos A, Pandya R, Duivenvoorden WC, Pinthus JH. Oxidative stress in prostate cancer: Changing research concepts towards a novel paradigm for prevention and therapeutics. Prostate Cancer and Prostatic Diseases. 2013;16(3):217-225.

2. Khandrika L, Kumar B, Koul S, Maroni P, Koul HK. Oxidative stress in prostate cancer. Cancer Lett. 2009;18;282(2):125-136.

3. Minciullo PL, Inferrera A, Navarra M, Calapai G, Magno C, Gange$\mathrm{mi}$ S. Oxidative stress in benign prostatic hyperplasia: A systematic review. Urol Int. 2014 [Epub ahead of print].

4. Eken A, Aydın A, Erdem O, Akay C, Sayal A, Somuncu I. Induced antioxidant activity in hospital staff occupationally exposed to ionizing radiation. Int J Radiat Biol. 2012;88(9):648-653.

5. Tüzün A, Değertekin B, Yeşilova Z, et al. Plasma MDA levels, GSH-Px activities and nitrite/nitrate levels in patients with familial Mediterranean fever. JCAM 2010;1(1):1-5.

6. Aebi H. Catalase in vitro. Methods Enzymol. 1984;105:121-126.

7. Merendino RA, Salvo F, Saija A, et al. Malondialdehyde in benign prostate hypertrophy: A useful marker? Mediat Inflamm. 2003;12(2):127-128.

8. Meagher EA, FitzGerald GA. Indices of lipid peroxidation in vivo: Strengths and limitations. Free Radic Biol Med. 2000;28(12):1745-1750.

9. Ray G, Batra S, Shukla NK, et al. Lipid peroxidation, free radical production and antioxidant status in breast cancer. Breast Cancer Res Treat. 2000;59(2):163-170.

10. Senthil K, Aranganathan S, Nalini N. Evidence of oxidative stress in the circulation of ovarian cancer patients. Clin Chim Acta. 2004;339(1-2):27-32.

11. Olinski R, Zastawny TH, Foksinski M, Barecki A, Dizdaroglu M. DNA base modifications and antioxidant enzyme activities in human benign prostatic hyperplasia. Free Radic Biol Med. 1995;18(4): 807-813.

12. Doğru-Abbasoğlu S, Aykaç-Toker G, Koçak T, Unlüer E, Uysal M. Antioxidant enzyme activities and lipid peroxides in the plasma of patients with benign prostatic hyperplasia or prostate cancer are not predictive. J Cancer Res Clin Oncol. 1999;125(7):402-404.

13. Almushatat AS, Talwar D, McArdle PA, et al. Vitamin antioxidants, lipid peroxidation and the systemic inflammatory response in patients with prostate cancer. Int J Cancer. 2006;118(4):1051-1053.

14. Yilmaz MI, Saglam K, Sonmez A, et al. Antioxidant system activation in prostate cancer. Biol Trace Elem Res. 2004;98(1):13-19.

15. Arsova-Sarafinovska Z, Eken A, Matevska N, et al. Increased oxidative/nitrosative stress and decreased antioxidant enzyme activities in prostate cancer. Clin Biochem. 2009;42(12):1228-1235.

16. Surapaneni KM, Venkata GR. Lipid peroxidation and antioxidant status in patients with carcinoma of prostate. Indian J Physiol Pharmacol. 2006;50(4):350-354.

17. Yossepowitch O, Pinchuk I, Gur U, Neumann A, Lichtenberg D, Baniel J. Advanced but not localized prostate cancer is associated with increased oxidative stress. J Urol. 2007;178(4):1238-1244.

18. Jung K, Seidel B, Rudolph B, et al. Antioxidant enzymes in malignant prostate cell lines and in primary cultured prostatic cells. Free Radic Biol Med. 1997;23(1):127-133.

19. Gaté L, Paul J, Ba GN, Tew KD, Tapiero H. Oxidative stress induced in pathologies: The role of antioxidants. Biomed Pharmacother. 1999;53(4):169-180.

20. Kumaraguruparan R, Subapriya R, Kabalimoorthy J, Nagini S. Antioxidant profile in the circulation of patients with fibroadenoma and adenocarcinoma of the breast. Clin Biochem. 2002;35(4):275-279.

21. Aydin A, Arsova-Sarafinovska Z, Sayal A, et al. Oxidative stress and antioxidant status in non-metastatic prostate cancer and benign prostatic hyperplasia. Clin Biochem. 2006;39(2):176-179.

22. Zhou JF, Xiao WQ, Zheng YC, Dong J, Zhang SM. Increased oxidative stress and oxidative damage associated with chronic bacterial prostatitis. Asian J Androl. 2006;8(3):317-323.

23. Baker AM, Oberley LW, Cohen MB. Expression of antioxidant enzymes in human prostatic adenocarcinoma. Prostate. 1997;1;32(4):229-233.

24. Battisti V, Maders LD, Bagatini MD, et al. Oxidative stress and antioxidant status in prostate cancer patients: Relation to Gleason score, treatment and bone metastasis. Biomed Pharmacother. 2011;65(7):516-524.
25. Biri H, Oztürk HS, Kaçmaz M, Karaca K, Tokuçoğlu H, Durak I. Activities of DNA turnover and free radical metabolizing enzymes in cancerous human prostate tissue. Cancer Invest. 1999;17(5):314-319.

26. Sapota A, Darago A, Taczalski J, Kilanowicz A. Disturbed homeostasis of zinc and other essential elements in the prostate gland dependent on the character of pathological lesions. Biometals. 2009;22(6):1041-1049.

27. Yan $\mathrm{M}$, Song $\mathrm{Y}$, Wong CP, Hardin $\mathrm{K}$, Ho E. Zinc deficiency alters DNA damage response genes in normal human prostate epithelial cells. J Nutr. 2008;138(4):667-673.

28. Christudoss P, Selvakumar R, Fleming JJ, Gopalakrishnan G. Zinc status of patients with benign prostatic hyperplasia and prostate carcinoma. Indian J Urol. 201;27(1):14-18.

29. Malm J, Hellman J, Hogg P, Lilja H. Enzymatic action of prostatespecific antigen (PSA or hK3): Substrate specificity and regulation by $\mathrm{Zn}(2+)$, a tight-binding inhibitor. Prostate. 2000;1;45(2):132-139.

30. Redman C, Scott JA, Baines AT, et al. Inhibitory effect of selenomethionine on the growth of three selected human tumor cell lines. Cancer Lett. 1998;125(1-2):103-110.

31. Redman C, Xu MJ, Peng YM, et al. Involvement of polyamines in selenomethionine induced apoptosis and mitotic alterations in human tumor cells. Carcinogenesis. 1997;18(6):1195-1202.

32. Griffin AC. Role of selenium in the chemoprevention of cancer. Adv Cancer Res. 1979;29:419-442.

33. Waters DJ, Shen S, Cooley DM, et al. Effects of dietary selenium supplementation on DNA damage and apoptosis in canine prostate. J Natl Cancer Inst. 2003;95(3):237-241.

34. Arshad MA, Bhadra S, Cohen RM, Subbiah MT. Plasma lipoprotein peroxidation potential: $A$ test to evaluate individual susceptibility to peroxidation. Clin Chem. 1991;37(10):1756-1758.

35. Brooks JD, Metter EJ, Chan DW, et al. Plasma selenium level before diagnosis and the risk of prostate cancer development. J Urol. 2001;166(6):2034-2038.

36. Lipsky K, Zigeuner R, Zischka M, et al. Selenium levels of patients with newly diagnosed prostate cancer compared with control group. Urology. 2004;63(5):912-916.

37. Muecke R, Klotz T, Giedl J, et al. Whole blood selenium levels (WBSL) in patients with prostate cancer (PC), benign prostatic hyperplasia (BPH) and healthy male inhabitants ( $\mathrm{HMI}$ ) and prostatic tissue selenium levels (PTSL) in patients with PC and BPH. Acta Oncol. 2009;48(3):452-456. 